\title{
ЕКОЛОГІЯ
}

\author{
УДК 911.8:504.054.05:556.531
}

\section{Олексій Миколайович Крайнюков,}

д. геогр. н., професор, кафедра екологічної безпеки та екологічної освіти, факультет екології,

Харківський національний університет імені В.Н. Каразіна,

пл. Свободи, 4, м. Харків, 61022, Україна, e-mail: alkraynukov@gmail.com, https://orcid.org/0000-0002-5264-3118;

Анастасія Вікторівна Якушева,

аспірант, НДУ «Український науково-дослідний інститут екологічних проблем», вул. Бакуліна, 6, м. Харків, 61166, Україна,

e-mail: yakusheva.nastasya@gmail.com, https://orcid.org/0000-0002-1950-735X

\section{ДОСЛІДЖЕННЯ МОЖЛИВОСТІ ВИКОРИСТАННЯ СЕRIODAPHNIA AFFINIS LILLJEBORG (CRUSTACEA) У КОРОТКОСТРОКОВОМУ ВИПРОБУВАННІ ПРИ ВСТАНОВЛЕННІ ЕКОЛОГІЧНИХ СТАНДАРТІВ ЯКОСТІ ВОДИ В УКРАЇНІ}

Аналіз функиіонуючих в різних краӥнах систем нормування якості поверхневих вод показав, щцо існує тенденція використання таких нормативів, дотримання яких дозволяє захищати водну екосистему та задовольняти потреби суспільства й галузей економіки. В основу таких нормативів покладено отримання екотоксикологічної інформації небезпечної хімічноі речовини на представниках водної екосистеми. Серед них одними із найбільи чутливих тест-організмів є ракоподібні з родини Daphniidae, які використовуються не тільки для встановлення норм якості води хімічних речовин, а й для оцінки якості стічних та поверхневих вод за токсикологічним показником. Для встановлення екологічних стандартів якості води в країнах ЄС рекомендується використовувати стандартизовану міжснародну методику з визначення токсичності хімічних речовин на Daphnia magna Straus (ОЕСР №202), однак в Україні у водоохоронній практиці найбільш популярним тесторганізмом є Ceriodaphnia affinis Lilljeborg (Daphnia sp.).

Робота спрямована на дослідження можливості використання Ceriodaphnia affinis Lilljeborg (Daphnia sp.) y короткостроковому випробуванні при встановленні екологічних стандартів води в Україні. У результаті проведених експериментальних досліджень на культурі ракоподібних з колекиії культур лабораторії еколого-токсикологічних досліджень ХНУ імені В. Н. Каразіна за умов використання методики ОЕСР №202 було встановлено метрологічні характеристики:

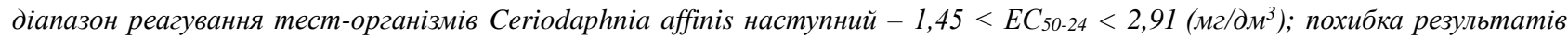

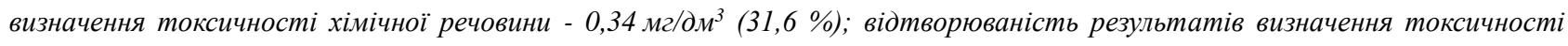

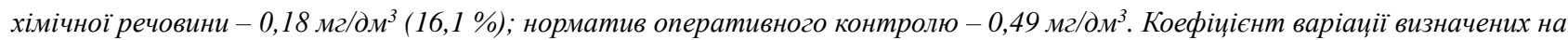
Ceriodaphnia affinis EC50-24 та ЕС50-48 для $\mathrm{K}_{2} \mathrm{Cr}_{2} \mathrm{O}_{7}$ склав 16,8\% та 15,9\% відповідно. Отримані результати свідчать про можливість використання культури ракоподібних Ceriodaphnia affinis у короткостроковому випробуванні при встановленні екологічних стандартів якості води в Україні.

Ключові слова: поверхневі води, токсичність, хімічні речовини, ефективна концентрація, Ceriodaphnia affinis Lilljeborg, метрологічні характеристики.

А.Н. Крайнюков, А. В. Якушева. ИССЛЕДОВАНИЕ ВОЗМОЖНОСТИ ИСПОЛЬЗОВАНИЯ СЕRIODАРНNІА AFFINIS LILLJEBORG (CRUSTACEA) В КРАTКОСРОЧНОМ ЕКСПЕРИМЕНТЕ ПРИ УСТАНОВЛЕНИИ ЭКОЛОГИЧЕСКИХ СТАНДАРТОВ КАЧЕСТВА ВОДЫ В УКРАИНЕ. Анализ функционирующих в разных странах систем нормирования качества поверхностных вод показал, что существует тенденция использования таких нормативов, при соблюдении которых обеспечивается защита водной экосистемы и удовлетворяются потребности общества и отраслей экономики. $B$ основу таких нормативов положено получение экотоксикологической информации опасных химических веществ на представителях водной экосистемы. Среди них одними из наиболее чувствительных тест-организмов являются ракообразные из семейства Daphniidae, которые используются не только для установления норм качества воды химических веществ, а и для оценки качества сточных и поверхностных вод по токсикологическим показателям. Для установления экологических стандартов качества воды в странах ЕС рекомендуется использовать стандартизированную международную методику определения токсичности химических веществ на Daphnia magna Straus (ОЭСР № 202). Однако в Украине в водоохранной практике наиболее популярным тест-организмом является Ceriodaphnia affinis Lilljeborg (Daphnia sp.).

Работа направлена на исследование возможности использования Ceriodaphnia affinis в краткосрочном испытании при установлении экологических стандартов качества воды в Украине. В результате проведенных экспериментальных исследований на культуре ракообразных из коллекции культур лаборатории эколого-токсикологических исследований ХНУ имени В. Н. Каразина при использовании методики ОЭСР № 202 было установлено метрологические характеристики: диапазон

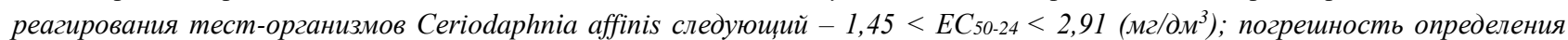

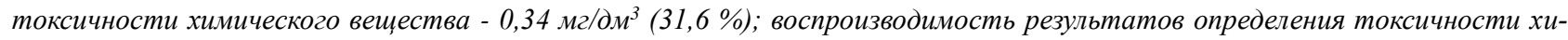

(с) Крайнюков О. М., Якушева А. В.

https://doi.org/10.26565/2410-7360-2019-51-14 


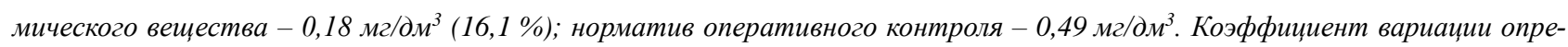
деленных на Ceriodaphnia affinis $\mathrm{EC}_{50-24}$ и $\mathrm{EC}_{50-48}$ для $\mathrm{K}_{2} \mathrm{Cr}_{2} \mathrm{O}_{7}$ составил 16,8 \% и 15,9\% соответственно. Полученные результаты свидетельствуют о возможности использования культуры ракообразных Ceriodaphnia affinis в краткосрочном испытании при установлении экологических стандартов качества воды в Украине.

Ключевые слова: поверхностные воды, токсичность, химические вещества, эфективная концентрация, Cегіодарһпіа affinis Lilljeborg, метрологические характеристики.

Постановка проблеми. На сьогодення та у найближчі десятиліття за даними ЮНЕСКО [1] існують тенденції підвищення попиту на воду та зниження iї якості в світі. Збільшення попиту на воду прогнозується в промисловості та енергетиці, в сільському та житлово-комунальному господарствах. У свою чергу, це стане причиною збільшення антропогенного навантаження, зокрема хімічного забруднення на поверхневі води, що знизить їхню якість та обмежить їхню придатність для задоволення різних потреб суспільства в подальшому.

Проблема збереження якості поверхневих вод від забруднення небезпечними хімічними речовинами $є$ актуальною для України. Серед підприємств, що функціонують на території країни, найбільш небезпечними для водної екосистеми $є$ підприємства хімічної, гірничорудної та нафтопереробної промисловості, великі тваринницькі комплекси та целюлозно-паперові комбінати. При надходженні до поверхневих вод небезпечних хімічних речовин разом зі стічними водами цих підприємств порушуються процеси життєдіяльності та відтворення водних організмів, кругообіг речовин, процеси самоочищення та біопродуктивності, що призводить до змін у структурно-функціональній організації водної екосистеми [2]. Таким чином обмежується придатність поверхневих вод для задоволення різних потреб суспільства та галузей економіки в подальшому.

Аналіз сучасних досліджень і публікацій.

Одним із методів оцінки й контролю за надходженням хімічних речовин до водної екосистеми є їхнє нормування відповідно до встановлених норм якості води. Аналіз функціонуючих в різних країнах систем нормування якості поверхневих вод показав, що існує тенденція використання таких нормативів, дотримання яких дозволяє захищати водну екосистему та задовольняти потреби суспільства й галузей економіки. Оскільки їхня особливість полягає в комплексному екосистемному підході до нормування якості поверхневих вод та захисті здоров'я людини, такі нормативи в країнах ЄС та Канаді мають статус екологічних [3-8].

В основу таких нормативів покладено отримання екотоксикологічної інформації небезпечної хімічної речовини на представниках водної екосистеми. Стандартизованими тест-організма- ми для встановлення екологічних нормативів $\epsilon$ мікроводорості (Pseudokirchneriella subcapitata (Korshikov) Hindak, Scenedesmus subspicatus Chodat, Chlorella vulgaris Beyerinck (Beijerinck)), ціанобактерії (Anabaena flos-aquae Brébisson ex Bornet \& Flauhault), ракоподібні (Daphnia magna Straus, Ceriodaphnia dubia Richard, Hyalella azteca Saussure), риби (Danio rerio HamiltonBuchanan, Oncorhynchus mykiss Walbaum) [3-9].

Питанню встановлення норм якості води хімічних речовин присвячена робота [10]. Авторами розглянуто три підходи для встановлення нормативів: коефіцієнт безпеки, розподіл видів за чутливістю, моделювання екосистеми AQUATOX. У результаті проведеного дослідження було визначено, що найбільший захист екосистеми забезпечується нормативом, який встановлено на основі коефіцієнту безпеки. Також зазначається, що при використанні тільки результатів визначення хронічної токсичності для встановлення норм якості води недооцінюється небезпечність короткострокового гострого токсичного впливу хімічної речовини, що нормується.

Необхідність удосконалення оцінки впливу хімічних речовин на навколишнє середовище, зокрема на водну екосистему, при проведенні екотоксикологічних досліджень хімічної речовини, що нормується, представлена в роботі [11]. Авторами розглянуто останні тенденції інтерпретації екотоксикологічних досліджень для встановлення нормативів i запропоновано дев'ять рекомендацій, завдяки яким результати випробувань будуть більш обгрунтованими і публічно визнаними.

У роботі [12] підіймається питання нормування надходження фармацевтичних препаратів до навколишнього середовища, зокрема до водної екосистеми, та актуальність встановлених нормативів. За результатами проведеного дослідження було встановлено, що для 88 \% (975 речовин) фармацевтичних препаратів екотоксикологічна інформація щодо небезпечності речовин для навколишнього середовища та здоров'я людини недостатньо висвітлена. Авторами запропоновано провести додаткові випробування цих речовин 3 використанням окрім стандартних тест-реакцій (іммобілізація, репродуктивність тощо), тест-реакцію зміни в поведінці тесторганізмів. 
Сучасна швидкість промислового виробництва наноматеріалів випереджає можливість проведення широкого спектру токсикологічних досліджень для оцінювання їхньої безпечності для навколишнього середовища. У зв'язку з цим авторами роботи [13] запропоновано використовувати набір короткострокових випробувань за допомогою методів in vitro та in vivo на клітинах риб, гемоцитах мідій, на ракоподібних та мікроводоростях.

Виділення невирішених раніше частин загальної проблеми.

Серед представників водної екосистеми одними із найбільш чутливих тест-організмів до небезпечних хімічних речовин $\epsilon$ ракоподібні 3 родини Daphniidae, які використовуються не тільки для встановлення норм якості води хімічних речовин, а й для оцінки якості стічних та поверхневих вод за токсикологічним показником.

Для можливості отримання відтворюваних результатів при проведенні процедур 3 визначення екотоксикологічної інформації хімічної речовини, що нормується, в лабораторіях різних країн світу, в країнах СС керівництвом [6] пропонується використовувати стандартизовані міжнародні методики ОЕСР для встановлення екологічних стандартів якості.

Однією з рекомендованих методик для встановлення екологічних стандартів якості є методика визначення токсичності хімічних речовин за показником іммобілізаціії ракоподібних 3 родини Daphniidae за 48 годин [14]. Бажаним видом є Daphnia magna, однак зазначається про можливість використання інших видів за умов дотримання критеріїв вірогідності, вказаних у методиці. В Україні для біотестування хімічних речовин, стічних та поверхневих вод на ракоподібних використовуються національні методики ДСТУ 4173-2003 [15], ДСТУ 4174:2003 [16] та КНД 211.1.4.055-97 [17], КНД 211.1.4.046-95 [18]. Стандартними тест-організмами, які пропонується використовувати окрім Daphnia magna, $є$ Ceriodaphnia affinis Lilljeborg.

Формулювання мети роботи. Метою роботи є апробація методики [14] на тест-організмі Ceriodaphnia affinis зі встановленням для неї метрологічних характеристик, що дозволить отримувати достовірну екотоксикологічну інформацію на відповідному тест-організмі при встановленні екологічних стандартів якості води хімічних речовин в Україні.

Виклад основного матеріалу дослідження. Для проведення дослідження було використано культуру ракоподібних Ceriodaphnia affinis з колекції культур лабораторії еколого-токсиколо- гічних досліджень Харківського національного університету імені В. Н. Каразіна.

Авторами було здійснено встановлення метрологічних характеристик для методики 3 визначення ефективної концентрації, що призводить до 50 \% іммобілізації ракоподібних Ceriodaphnia affinis $\left(\mathrm{EC}_{50}\right)$ за 24 та 48 годин [14] відповідно до керівного документа $[19,20]$. При проведенні процедур з визначення ефективної концентрації $\mathrm{EC}_{50}$ еталонної хімічної речовини $\mathrm{K}_{2} \mathrm{Cr}_{2} \mathrm{O}_{7}$ на тест-організмах були витримані умови, які свідчать про достовірність отриманих даних: концентрація розчиненого кисню наприкінці випробування була $\geq 3$ мг/дм³; у контролі відсоток іммобілізованих тест-організмів наприкінці випробування становив не більше ніж $10 \%$ [14].

До отриманих експериментальних даних токсичності для знаходження концентрації, що призводить до 50 \% іммобілізації тест-організмів, застосовували метод нелінійної регресії. Для цього використовували програмне забезпечення Graph Pad Prism 8 [20].

Результати експериментальних досліджень iз визначення $\mathrm{EC}_{50-24} \quad \mathrm{~K}_{2} \mathrm{Cr}_{2} \mathrm{O}_{7}$ на Ceriodaphnia affinis представлені на рис. 1.

Отримані значення $\mathrm{EC}_{50}$ еталонної хімічної речовини $\mathrm{K}_{2} \mathrm{Cr}_{2} \mathrm{O}_{7}$ для тест-організмів Ceriodaphnia affinis за 24 години наведені в таблиці 1.

Усі подальші розрахунки, які необхідні для встановлення метрологічних характеристик, здійснювали за допомогою програмного забезпечення Microsoft Office 2016 в середовищі Excel. Отримані значення EC $_{50-24}$ для Ceriodaphnia affinis (табл. 1) перевіряли на наявність надмірної похибки за $\beta$-критерієм:

$$
\beta=\frac{\| x_{n}-\overline{\mathrm{M}} \mid}{s},
$$

де $S$ - середньо квадратичне відхилення;

$X_{n}-$ результат досліду з визначення $\mathrm{EC}_{50-24}$;

$\bar{X}$ - середнє арифметичне значення.

Результати експериментальних досліджень 3 визначення $\mathrm{EC}_{50-24} \mathrm{~K}_{2} \mathrm{Cr}_{2} \mathrm{O}_{7}$ на Ceriodaphnia affinis використовували при встановленні діапазону чутливості культури, який розраховують за формулою:

$$
\bar{X}-1,96 \times \sigma<X_{\kappa}<\bar{X}+1,96 \times \sigma,
$$

де $X_{\kappa}$ - концентрація, за якої досягається критерій токсичності ( $\left.\mathrm{EC}_{50-24}\right)$;

$\bar{X}$ - середнє арифметичне значення;

$\sigma$ - значенння внутрішньолабораторної відтворюваності.

Для знаходження значення внутрішньолабораторної відтворюваності $\sigma$ результатів визначення токсичності хімічної речовини використовували наступну формулу:

$$
\sigma=S \times \gamma(f),
$$

де $S$ - середньо квадратичне відхилення; 


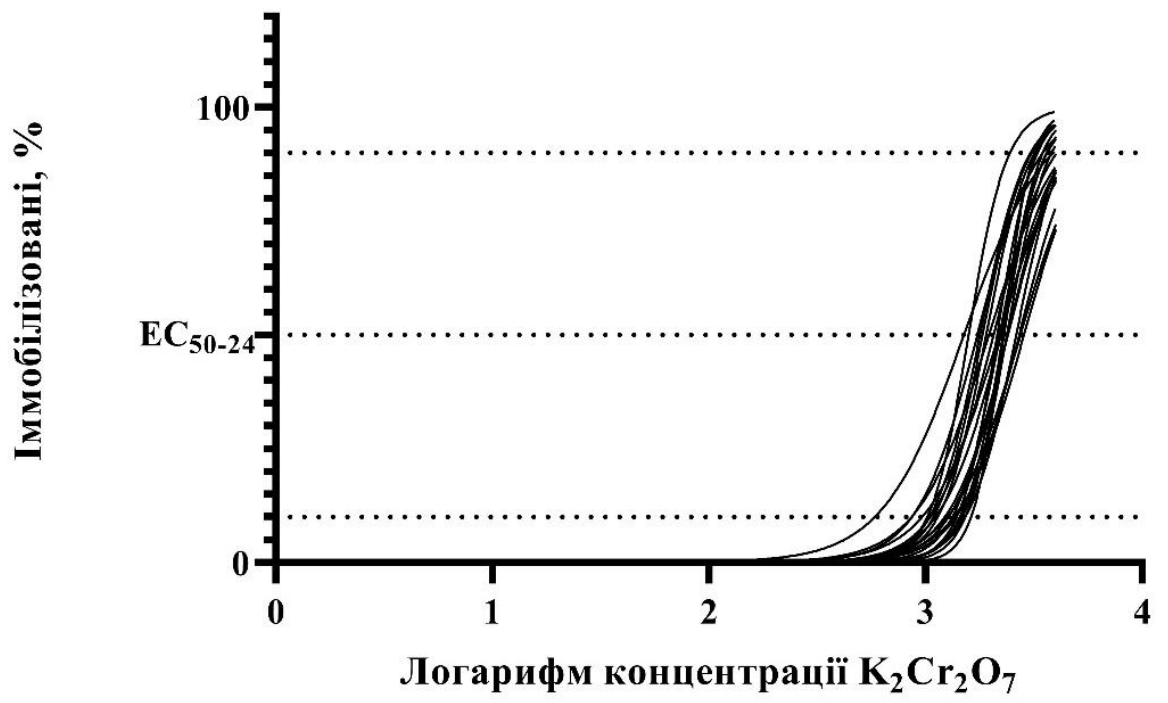

Рис. 1. Результати експериментальних досліджень з визначення $\mathrm{EC}_{50-24} \mathrm{~K}_{2} \mathrm{Cr}_{2} \mathrm{O}_{7}$ на Ceriodaphnia affinis

Отримані значення $\mathrm{EC}_{50}$ еталонної хімічної речовини $\mathrm{K}_{2} \mathrm{Cr}_{2} \mathrm{O}_{7}$ за 24 год.

Таблиия 1 на ракоподібних Ceriodaphnia affinis

\begin{tabular}{|c|c|c|c|c|}
\hline $\begin{array}{l}\text { Номер } \\
\text { досліду }\end{array}$ & $\begin{array}{l}\mathrm{EC}_{50-24,} \\
\mathrm{M \Gamma} / \mathrm{дM}^{3}\end{array}$ & Сер. арифм & $\begin{array}{l}\text { Коефіцієнт } \\
\text { варіації, \% }\end{array}$ & $\begin{array}{c}\text { Середньо-квадратичне } \\
\text { відхилення Si }\end{array}$ \\
\hline 1 & 2,306 & \multirow{22}{*}{2,19} & \multirow{22}{*}{$16,8 \%$} & \multirow[t]{22}{*}{ 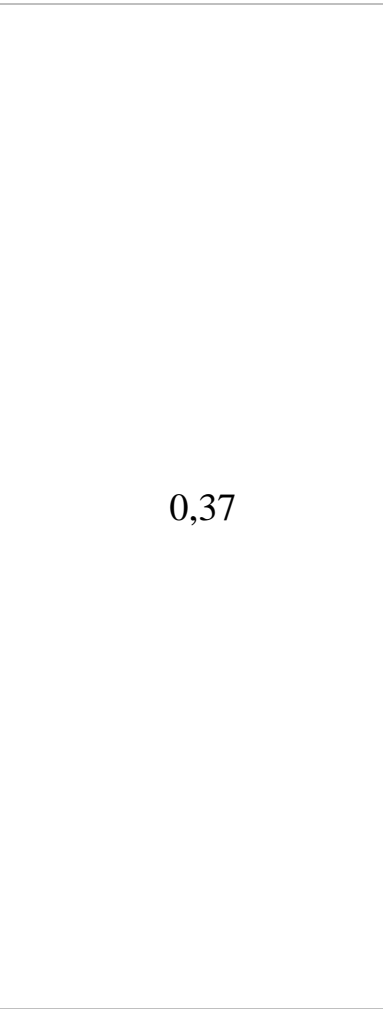 } \\
\hline 2 & 2,404 & & & \\
\hline 3 & 2,745 & & & \\
\hline 4 & 2,395 & & & \\
\hline 5 & 1,505 & & & \\
\hline 6 & 1,736 & & & \\
\hline 7 & 2,181 & & & \\
\hline 8 & 2,623 & & & \\
\hline 9 & 1,964 & & & \\
\hline 10 & 2,235 & & & \\
\hline 11 & 2,062 & & & \\
\hline 12 & 2,711 & & & \\
\hline 13 & 2,849 & & & \\
\hline 14 & 2,279 & & & \\
\hline 15 & 1,907 & & & \\
\hline 16 & 1,582 & & & \\
\hline 17 & 1,835 & & & \\
\hline 18 & 2,289 & & & \\
\hline 19 & 2,142 & & & \\
\hline 20 & 1,786 & & & \\
\hline 21 & 2,204 & & & \\
\hline 22 & 2,377 & & & \\
\hline
\end{tabular}

$\gamma(f)$ - коефіцієнт, який враховує зміщеність значення середньоквадратичного відхилення, $\gamma$ (f) для $f=21$ становить 1,013 .

Середнє квадратичне відхилення розраховували за формулою:

$$
S=\sqrt{\frac{\sum_{n=1}^{N}\left(X_{n}-\overline{\mathrm{X}}\right)^{2}}{N-1}}
$$

де $X_{n}$ - результат досліду з визначення $\mathrm{EC}_{50-24}$;
$\bar{X}$ - середнє арифметичне значення; $N$ - кількість проведених дослідів.

Встановлений діапазон чутливості тесторганізмів Ceriodaphnia affinis наступний:

$2,19-1,96 \times 0,18<\mathrm{EC}_{50-24}<2,19+1,96 \times 0,18$; $1,46<\mathrm{EC}_{50-24}<2,92\left(\right.$ мг/дм $\left.{ }^{3}\right)$.

Для встановлення значення відтворюваності методики з визначення ефективної концентрації, що призводить до 50\% іммобілізації ракоподіб- 
них Ceriodaphnia affinis $\left(\mathrm{EC}_{50}\right)$ за 48 годин, використовували формули (5), (6):

$$
\begin{gathered}
\sigma=S \times \gamma(f), \\
\sigma(\%)=\frac{s \times y(f)}{\bar{x}} \times 100,
\end{gathered}
$$

де $\mathrm{S}$ - середньо квадратичне відхилення;

$\gamma(f)$ - коефіцієнт, який враховує зміщеність значення середньоквадратичного відхилення, $\gamma(f)$ для $f=21$ становить 1,013 ;
$\bar{X}$ - середнє арифметичне значення.

Результати експериментальних досліджень 3 визначення $\mathrm{EC}_{50-48} \mathrm{~K}_{2} \mathrm{Cr}_{2} \mathrm{O}_{7}$ на Ceriodaphnia affinis представлені на рис. 2 та в таблиці 2.

Перед використанням формул (5) та (6) отримані значення $\mathrm{EC}_{50-48}$ для Ceriodaphnia affinis (табл. 2) перевіряли на наявність надмірної похибки за $\beta$-критерієм за формулою (1).

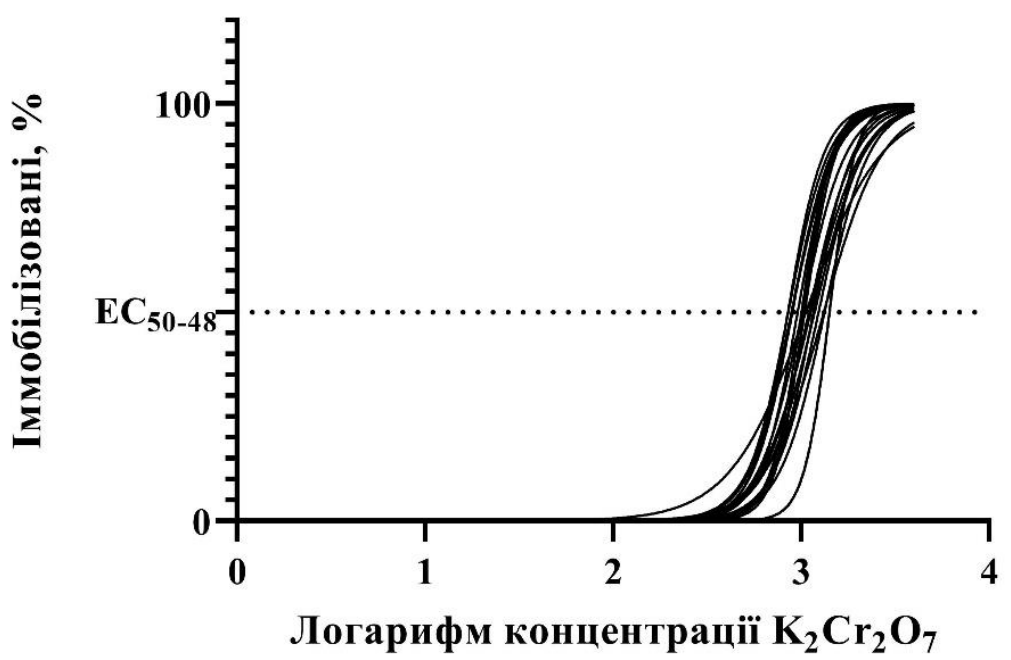

Рис. 2. Результати експериментальних досліджень з визначення $\mathrm{EC}_{50-48} \mathrm{~K}_{2} \mathrm{Cr}_{2} \mathrm{O}_{7}$ на Ceriodaphnia affinis

Таблиия 2

Отримані значення $\mathrm{EC}_{50}$ еталонної хімічної речовини $\mathrm{K}_{2} \mathrm{Cr}_{2} \mathrm{O}_{73 a} 48$ год. на ракоподібних Ceriodaphnia affinis

\begin{tabular}{|c|c|c|c|c|}
\hline $\begin{array}{c}\text { Номер } \\
\text { досліду }\end{array}$ & $\mathrm{EC}_{50-48, \mathrm{Mг} / \mathrm{дm}^{3}}$ & Сер. арифм. & $\begin{array}{c}\text { Коефіціснт } \\
\text { варіації, } \%\end{array}$ & $\begin{array}{c}\text { Середньо-квадратичне } \\
\text { відхилення S }\end{array}$ \\
\hline 1 & 1,318 & & \\
\hline 2 & 1,057 & & \\
\hline 3 & 1,011 & & \\
\hline 4 & 0,957 & & \\
\hline 5 & 1,033 & & \\
\hline 6 & 0,896 & & \\
\hline 7 & 0,887 & & \\
\hline 8 & 1,33 & & \\
\hline 9 & 0,89 & & \\
\hline 10 & 1,16 & & \\
\hline 11 & 1,004 & & \\
\hline 12 & 1,413 & & \\
\hline 13 & 1,413 & & \\
\hline 14 & 1,178 & & \\
\hline 15 & 1,1 & & \\
\hline 16 & 1,043 & & \\
\hline 17 & 1,033 & & \\
\hline 18 & 0,853 & & \\
\hline 19 & 1,236 & & \\
\hline 20 & 0,849 & & \\
\hline 21 & 1,1 & & \\
\hline 2 & 1,123 & & \\
\hline
\end{tabular}


Таким чином, відтворюваність результатів визначення токсичності хімічної речовини випробуваної методики:

$$
\sigma=0,18\left(\text { мг/дм }{ }^{3}\right) \text { та } \sigma(\%)=16,1 \% \text {; }
$$

Для розрахунку похибки результатів визначення токсичності хімічної речовини випробуваної методики використовували формули (7), (8):

$$
\begin{gathered}
\Delta=1,96 \times \sigma, \\
\Delta(\%)=1,96 \times \sigma(\%),
\end{gathered}
$$

де $\sigma$ та $\sigma(\%)$ - відтворюваність результатів визначення токсичності хімічної речовини випробуваної методики.

Отже похибка результатів визначення ефективної концентрації $\mathrm{K}_{2} \mathrm{Cr}_{2} \mathrm{O}_{7}$, що призводить до $50 \%$ іммобілізації ракоподібних Ceriodaphnia affinis $\left(\mathrm{EC}_{50}\right)$ за 48 годин, за умов використання методики [14] наступна:

$$
\Delta=1,96 \times 0,18=0,34\left(\text { мг } / \text { дм }^{3}\right)
$$$$
\Delta(\%)=1,96 \times 14,19(\%)=31,6(\%) \text {. }
$$

3 метою оперативної перевірки значення $\mathrm{EC}_{50-48}$, отриманого за відповідною методикою, було встановлено норматив оперативного контролю за наступною формулою (9):

$$
\mathrm{D}=2,77 \times \sigma,
$$

де $\sigma$ - відтворюваність результатів визначення токсичності хімічної речовини випробуваної методики.

Звідси норматив оперативного контролю результатів визначення ефективної концентрації $\mathrm{K}_{2} \mathrm{Cr}_{2} \mathrm{O}_{7}$, що призводить до $50 \%$ іммобілізації ракоподібних Ceriodaphnia affinis $\left(\mathrm{EC}_{50}\right)$ за 48 го- дин, для визначеної методики [14] складає 0,49 $\mathrm{мг} /$ дм$^{3}$.

Висновки. Отже у результаті проведених експериментальних досліджень на культурі ракоподібних Ceriodaphnia affinis з колекції культур лабораторії еколого-токсикологічних досліджень ХНУ імені В. Н. Каразіна авторами було апробовано методику ОЕСР № 202 [14], яку рекомендовано до використання при встановленні екологічних стандартів якості води. Коефіцієнт варіації визначених на Ceriodaphnia affinis $\mathrm{EC}_{50-24}$ та $\mathrm{EC}_{50-48}$ для $\mathrm{K}_{2} \mathrm{Cr}_{2} \mathrm{O}_{7}$ склав $16,8 \%$ та $15,9 \%$, відповідно. На основі отриманих даних було встановлено метрологічні характеристики випробуваної методики: діапазон чутливості тесторганізмів Ceriodaphnia affinis наступний - 1,45 $<\mathrm{EC}_{50-24}<2,91($ мг/дм³); похибка результатів визначення токсичності хімічної речовини - 0,34 мг/дм ${ }^{3}$ (31,6 \%); відтворюваність результатів визначення токсичності хімічної речовини $0,18 \mathrm{мг} /$ дм $^{3}(16,1 \%)$, норматив оперативного контролю - 0,49 мг/дм³ .

Таким чином, у короткостроковому випробуванні при встановленні екологічних стандартів якості води в Україні можливо використовувати культуру ракоподібних Ceriodaphnia affinis з колекції культур лабораторії екологотоксикологічних досліджень ХНУ імені В.Н. Каразіна. Встановлені метрологічні характеристики це підтверджують.

1. The United Nations World Water Development Report 2018: Nature-Based Solutions for Water [Електронний pеcypc]. - Paris: UNESCO. - Режим достуny: http://unesdoc.unesco.org/images/0026/002614/261424e.pdf

2. Брагінський, Л. П. Гідроекологічна токсикометрія та біоіндикація забруднень: Теорія, методи, практика використання [Текст] / I. Т. Олексів, Л. П. Брагінський. - Львів: Світ, 1995. - 440 с.

3. Directive 2000/60/EC of the European Parliament and of the Council of establishing a framework for Community action in the field of water policy (2000). https://eur-lex.europa.eu/legal-content/EN/TXT/? uri=celex:32000L0060

4. Водний Кодекс Украӥни від 06.06.1985 р. № 213/95-ВР [Електронний ресурс] // База даних «Законодавство України» / ВР Украӥни. - Режим достуnу: http://zakon3.rada.gov.ua/laws/show/213/95-\%D0\%B2\%D1\%80

5. Методические указания по установлению эколого - рыбохозяйственных нормативов (ПДК и ОБУВ) загрязняющих вещзеств для воды водных объектов, имеющих рыбохозяйственное значение [Текст] // ред. О. Ф. Филенко, С. А. Соколова. - М.: ВНИРО, 1998. - 145 c.

6. Guidance Document № 27:Technical guidance for deriving environmental quality standards [Електронний реcypc]. - Brussels: Directorate General Environment of the European Commission. - Pежим доступy: https://circabc.europa.eu/sd/a/Occ3581b-5f65-4b6f-91c6-433ale947838/TGD-EQS\%20CISWFD\%2027\%20EC\%202011.pdf.

7. A protocol for the derivation of water quality guidelines for the protection of aquatic life 2007 [Електронний pecypc]. - Canadian Council of Ministers of the Environment, Winnipeg. - Peжuм docmyny: http://ceqgrcqe.ccme.ca/download/en/220.

8. Guidelines for Deriving Numerical National Water Quality Criteria for the Protection Of Aquatic Organisms and Their Uses [Електронний ресурс]. - U.S. Environmental Protection Agency. - Pежим доступу: https://www.epa.gov/sites/production/files/2016-02/documents/guidelines-water-quality-criteria.pdf.

9. Об утверждении Методических указаний по разработке нормативов качества воды водных объектов рыбохозяйственного значения, в том числе нормативов предельно допустимых концентраций вредных веществ в водах водных объектов рыбохозяйственного значения (с изменениями на 22 декабря 2016 года) [Електронний ресурс]. - Росрыболовство. - Режим доступу: http://docs.cntd.ru/document/902172637.

10. Gredelj A. Deriving predicted no-effect concentrations (PNECs) for emerging contaminants in the river Po, Italy, using three approaches: Assessment factor, species sensitivity distribution and AQUATOX ecosystem modelling / 
Gredelj A., Barausse A., Grechi L., Palmeri L. // Environment International. - Volume 119, 2018. - P. 66-78 [https://doi.org/10.1016/j.envint.2018.06.017].

11. Improving environmental risk assessments of chemicals: Steps towards evidence-based ecotoxicology [Martin O. V., Adams J., Beasley A., Belangers S and other]// Environment International. - Volume 128, 2019. - P. 210217 [https://doi.org/10.1016/j.envint.2019.04.053].

12. Pharmacology beyond the patient - The environmental risks of human drugs [Gunnarsson L., Snape J. R., Verbruggen B.,Owen S.F. and other] // Environment International. - Volume 129, 2019. - P. 320-332 [https://doi.org/10.1016/j.envint.2019.04.075].

13. Investigating the Impact of Manufacturing Processes on the Ecotoxicity of Carbon Nanofibers: A Multi-Aquatic Species Comparison [Barrick A., Châtel A., Manier N., Kalman J. and other]// Environmental toxicology and chemistry. 2019. [https://doi.org/10.1002/etc.4537].

14. OECD 2004. Daphnia sp. Acute Immobilisation Test, OECD Guideline for the testing of chemicals, Guideline 202 [https://doi.org/10.1787/9789264069947-en].

15. ДСТУ 4173-2003. Якість води. Визначання гострої летальної токсичності на Daphnia magna Straus ma Ceriodaphnia affinis Lilljeborg (Cladocera, Crustacea) (ISO 6341:1996, MOD).

16. ДСТУ 4174-2003. Якість води. Визначання сублетальної та хронічної токсичності хімічних речовин та води на Daphnia magna Straus i Ceriodaphnia affinis Lilljeborg (Cladocera, Crustacea) (ISO 1076:2000, MOD).

17. КНД 211.1.4.055-97. Методика визначення гострої летальної токсичності води на ракоподібних Сегіоdaphnia affinis Lilljeborg. Затв. наказом Мінприроди України від 21.05.97 № 68.

18. КНД 211.1.4.046-95. Біотестування та визначення рівнів гострої летальної токсичності зворотних вод, які відводяться у водні об'єкти. Методика. Затв. наказом Мінекобезпеки Украӥни від 30.05.95 № 47.

19. КНД 211.1.0.051-96. Атестація методик біотестування. Затв. наказом Мінекобезпеки України від 22.01.97 p. - №9. -33 c.

20. Current Approaches in the Statistical Analysis of Ecotoxicity Data. - OECD, $2014 . \quad-\quad P . \quad 114$ [https://dx.doi.org/10.1787/9789264085275-en].

Внесок авторів: всі автори зробили рівний внесок у цю роботу.

UDC 911.8:504.054.05:556.531

\section{Oleksii Krainiukov,}

Doctor of Sciences(Geography), Professor,

Department of EnvironmentalMonitoring and Nature Management, School of Ecology,

V.N. Karazin Kharkiv National University, 6 Svobody Sq., Kharkiv, 61022, Ukraine, e-mail: alkraynukov@gmail.com, https://orcid.org/0000-0002-5264-3118;

Anastasiia Yakusheva,

PhD Student, Ukrainian Scientific and Research Institute of Ecological Problems,

6 Bakulina St., Kharkiv, 61166, Ukraine,

e-mail: yakusheva.nastasya@gmail.com, https://orcid.org/0000-0002-1950-735X

\section{RESEARCH OF THE POSSIBILITY OF USING CERIODAPHNIA AFFINIS LILLJEBORG (CRUSTACEA) IN A SHORT-TERM TEST WHILE SETTING EOLOGICAL QUALITY STANDARDS IN UKRAINE}

Formulation of the problem. Regulation of hazardous chemicals admission to surface water is carried out by means of appropriate water quality standards. Researching the systems of surface water quality regulation in different countries, it has been determined that there is a tendency to use standards for the protection of the aquatic ecosystem and for meeting the needs of society and industries - environmental quality standards. Such standards are based on obtaining ecotoxicological information of a dangerous chemical substance on the representatives of the aquatic ecosystem. Among them, some of the most sensitive test organisms are crustaceans from the Daphniidae family. They are used to establish water quality standards for chemicals, to assess the quality of wastewater and surface water using a toxicological indicator. It is recommended to use a standardized international methodology to assess effects of chemicals on Daphnia magna Straus (OECD No. 202 ) to establish environmental water quality standards in EU countries. However, in Ukraine, in water protection practice, the most popular test organism is Ceriodaphnia affinis Lilljeborg (Daphnia sp.).

The purpose of the article. In order to set ecological standards for water quality of chemicals in Ukraine, the authors proposed to test the OECD No. 202 methodology using Ceriodaphnia affinis test organisms and to establish metrological characteristics for it.

Presentation of the main research material. The authors tested the OECD methodology No. 202 [21] on the crustacean culture Ceriodaphnia affinis from the culture collection of the Laboratory of Ecological and 
Toxicological Research, the V. N. Karazin KhNU. The coefficient of variation of EC50-24 and EC50-48 $\mathrm{K}_{2} \mathrm{Cr}_{2} \mathrm{O}_{7}$ was $16,8 \%$ and $15,9 \%$ respectively. Based on the data obtained, the metrological characteristics of the tested method were established: the response range of the test organisms Ceriodaphnia affinis is the following $-1,45<$ EC50-24 $<2,91\left(\mathrm{mg} / \mathrm{dm}^{3}\right)$; reproducibility of the results of determining the toxicity of a chemical substance $-0,18 \mathrm{mg} / \mathrm{dm} 3(16,1 \%)$; the error in the results of determining the toxicity of a chemical substance $-0,34 \mathrm{mg} / \mathrm{dm}^{3}(31.6 \%)$; standard of operational control $-0,49 \mathrm{mg} / \mathrm{dm}^{3}$.

Scientific novelty and practical significance. The findings confirm the possibility of using Ceriodaphnia affinis in a short-term test in setting environmental water quality standards in Ukraine.

Keywords: surface water, toxicity, chemicals, effective concentration, Ceriodaphnia affinis Lilljeborg, metrological characteristics.

\section{References}

1. UNESCO (2018). The United Nations World Water Development Report 2018: Nature-Based Solutions for Water. Paris. UNESCO. http://unesdoc.unesco.org/images/0026/002614/261424e.pdf

2. Brahinskyi L. P., Oleksiv I. T. (1995). Hidroekolohichna toksykometriia ta bioindykatsiia zabrudnen: Teoriia, metody, praktyka vykorystannia. Lviv, Svit, 440.

3. Directive 2000/60/EC of the European Parliament and of the Council of establishing a framework for Community action in the field of water policy (2000). https://eur-lex.europa.eu/legal-content/EN/TXT/?uri=celex:32000L0060

4. Vodnyi Kodeks Ukrainy vid 06.06.1985 r. № 213/95-VR. http://zakon3.rada.gov.ua/laws/show/213/95$\% D 0 \% B 2 \% D 1 \% 80$

5. Filenko O. F., Sokolova S. A. (1998). Metodicheskie ukazanija po ustanovleniju jekologo - rybohozjajstvennyh normativov (PDK i OBUV) zagrjaznjajushhih veshhestv dlja vody vodnyh ob"ektov, imejushhih rybohozjajstvennoe znachenie. M., VNIRO, 145.

6. Guidance Document № 27:Technical guidance for deriving environmental quality standards (2011). https://circabc.europa.eu/sd/a/0cc3581b-5f65-4b6f-91c6-433ale947838/TGD-EQS\%20CISWFD\%2027\%20EC\%202011.pdf.

7. A protocol for the derivation of water quality guidelines for the protection of aquatic life (2007). Canadian Council of Ministers of the Environment, Winnipeg. http://ceqg-rcqe.ccme.ca/download/en/220.

8. Guidelines for Deriving Numerical National Water Quality Criteria for the Protection Of Aquatic Organisms and Their Uses. U.S. Environmental Protection Agency. https://www.epa.gov//sites/production/files/201602/documents/guidelines-water-quality-criteria.pdf.

9. Ob utverzhdenii normativov kachestva vody vodnyh ob"ektov rybohozjajstvennogo znachenija, $v$ tom chisle normativov predel'no dopustimyh koncentracij vrednyh veshhestv $v$ vodah vodnyh ob"ektov rybohozjajstvennogo znachenija, ot 13.01.2017 g. № 45203. https://minjust.consultant.ru/documents/22231?items=1 \&page=1.

10. Gredelj A., Barausse A., Grechi L., Palmeri L. (2018). Deriving predicted no-effect concentrations (PNECs) for emerging contaminants in the river Po, Italy, using three approaches: Assessment factor, species sensitivity distribution and AQUATOX ecosystem modelling. Environment International. 119, 66-78 [https://doi.org/10.1016/j.envint.2018.06.017].

11. Martin O. V., Adams J., Beasley A., Belangers $S$ and other (2019). Improving environmental risk assessments of chemicals: Steps towards evidence-based ecotoxicology. Environment International. 128, 210-217 [https://doi.org/10.1016/j.envint.2019.04.053].

12. Gunnarsson L., Snape J. R., Verbruggen B.,Owen S. F. and other (2019) Pharmacology beyond the patient - The environmental risks of human drugs. Environment International. 129, 320-332 [https://doi.org/10.1016/j.envint.2019.04.075].

13. Barrick A., Châtel A., Manier N., Kalman J. and other (2019) Investigating the Impact of Manufacturing Processes on the Ecotoxicity of Carbon Nanofibers: A Multi-Aquatic Species Comparison. Environmental toxicology and chemistry. [https://doi.org/10.1002/etc.4537].

14. OECD (2004). Daphnia sp. Acute Immobilisation Test, OECD Guideline for the testing of chemicals, Guideline 202 [https://doi.org/10.1787/9789264069947-en].

15. DSTU 4173 (2003). Jakistj vody. Vyznachannja ghostroji letaljnoji toksychnosti na Daphnia magna Straus ta Ceriodaphnia affinis Lilljeborg (Cladocera, Crustacea) (ISO 6341:1996, MOD).

16. DSTU 4174 (2003). Jakistj vody. Vyznachannja subletaljnoji ta khronichnoji toksychnosti khimichnykh rechovyn ta vody na Daphnia magna Straus i Ceriodaphnia affinis Lilljeborg (Cladocera, Crustacea) (ISO 1076:2000, MOD).

17. KND 211.1.4.055-97 (1997). Metodyka vyznachennja ghostroji letaljnoji toksychnosti vody na rakopodibnykh Ceriodaphnia affinis Lilljeborg. Zatv. nakazom Minpryrody Ukrajiny vid 21.05.97 № 68.

18. KND 211.1.4.046-95 (1995). Biotestuvannja ta vyznachennja rivniv ghostroji letaljnoji toksychnosti zvorotnykh vod, jaki vidvodjatjsja u vodni ob’jekty. Metodyka. Zatv. nakazom Minekobezpeky Ukrajiny vid 30.05.95 № 47.

19. KND 211.1.0.051-96 (1996). Atestacija metodyk biotestuvannja. Zatv. nakazom Minekobezpeky Ukrajiny vid 22.01 .97 r. $9,33$.

20. OECD (2014). Current Approaches in the Statistical Analysis of Ecotoxicity Data. 114 [https://dx.doi.org/10.1787/9789264085275-en]. 